\title{
Assessing exposure to food additives in the diets of Irish children and teenagers using three different scenarios
}

\author{
A. Connolly, E. Boylan, A. Hearty, A. Nugent and M. J. Gibney \\ UCD Institute of Food and Health, Belfield, Dublin 4, Republic of Ireland
}

Exposure analyses of seven target additives in the diets of Irish children and teenagers were conducted - six colours (Sunset Yellow (E211), Carmoisine (E122), Tartrazine (E102), Ponceau 4R (E124), Allura Red (E129) and Quinoline Yellow (E104)) and one preservative-Sodium Benzoate (E211).

The Irish National Food and Ingredient Database (INFID) is a multi-faceted database that records, at the brand level, detailed information of all ingredients in foods consumed by participants in the National Children's Food Consumption Survey (NCFS) (2003-2004) ${ }^{(1)}$ and the National Teenager's Food Survey $(2005-2006)^{(2)}$. SPSS food files generated from the NCFS and National Teenagers' Food Survey recorded data for each food consumed per eating occasion per subject per day. Each eating occasion was recorded at the brand level, thus linking to the brand codes in INFID. This allowed chemical occurrence data for the seven target additives to be directly related to food intake.

Food groups were developed based on those outlined in regulation ${ }^{(3)}$. Three scenarios were run to assess the exposure of Irish children and teenagers to the seven target additives. Scenario 1 uses maximum permitted levels (MPL) and assumes that if the additive is legally permitted, it is always present. Scenario 2 uses MPL, but applies them to chemical occurrence data (from INFID). Scenario 3 uses chemical concentration data with chemical occurrence data. Chemical concentration data were obtained from four sources. Deterministic exposure assessments were conducted using Crème software ${ }^{(4)}$. Data presented below refer to three of the food additives with higher exposure.

Table 1. Mean intakes (and SD) for consumers only from the three scenarios for three of the target additives

\begin{tabular}{|c|c|c|c|c|c|c|}
\hline & \multicolumn{3}{|c|}{ Children (mg/kg/body weight) } & \multicolumn{3}{|c|}{ Teenagers (mg/kg/body weight) } \\
\hline & E110 (ADI: 0-2.5)* & E124 (ADI: $0-0.7)^{*}$ & E104 (ADI: 0-2.5)* & E110(ADI: 0-2.5)* & E124(ADI: $0-0.7$ )* & E104(ADI: $0-2.5)^{*}$ \\
\hline Scenario 1 & $0.66(0.36)$ & $0.66(0.36)$ & $1.26(0.69)$ & $0.50(0.35)$ & $0.50(0.35)$ & $0.81(0.50)$ \\
\hline Scenario 2 & $0.04(0.06)$ & $0.01(0.01)$ & $0.09(0.01)$ & $0.04(0.04)$ & $0.03(0.02)$ & $0.04(0.05)$ \\
\hline \multicolumn{7}{|l|}{ Scenario 3} \\
\hline Industry $0.03(0.06)$ & $0.01(0.01)$ & $0.08(0.09)$ & $0.03(0.04)$ & $0.01(0.01)$ & $0.04(0.05)$ & \\
\hline FSAI & $0.03(0.05)$ & $0.01(0.02)$ & $0.03(0.03)$ & $0.03(0.04)$ & $0.007(0.01)$ & $0.01(0.02)$ \\
\hline UKFSA & $0.03(0.06)$ & $0.01(0.04)$ & $0.06(0.09)$ & $0.03(0.04)$ & $0.009(0.01)$ & $0.02(0.02)$ \\
\hline FSANZ & $0.03(0.06)$ & $0.01(0.02)$ & $0.02(0.09)$ & $0.03(0.04)$ & $0.001(0.005)$ & $0.001(0.009)$ \\
\hline
\end{tabular}

FSAI, Tood Safety Authority of Ireland; UKFSA, United Kingdom Food Standards Agency; FSANZ, Food Standards of Australia, New Zealand.

*Acceptable daily intakes, milligram per kilogram of body weight.

All results were below acceptable daily intakes (ADI), for both the most conservative (scenario 1) and the least conservative results (scenario 3). The results suggest that the application of chemical occurrence and concentration data is necessary to provide realistic chemical exposure analyses.

1. Irish Universities Nutrition Alliance (2004) The National Children's Food Survey. http://www.iuna.net/docs/bg_ncfs.pdf

2. Irish Universities Nutrition Alliance (2006) The National Teenager's Food Survey. http://www.iuna.net/docs/teenchapter1background.pdf

3. European Union (1994). EU Directive No. 94/36/EC. European Parliament and Council Directive 94/36/EC of 30 June 1994 on colours for use in foodstuffs. Official Journal of the European Communities. L237, 13-29.

4. Crème Software Ltd. http://cremesoftware.com/ 